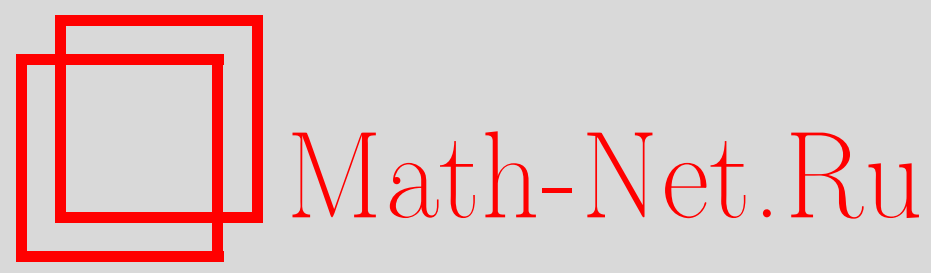

Г. Ф. Егорова, Периодические решения математической модели процесса внутреннего врезного шлифования, Вестн. Сам. гос. техн. ун-та. Сер. Физ.-мат. науки, 1999, выпуск 7, 197-199

DOI: https://doi.org/10.14498/vsgtu229

Использование Общероссийского математического портала Math-Net.Ru подразумевает, что вы прочитали и согласны с пользовательским соглашением http: //www.mathnet.ru/rus/agreement

Параметры загрузки:

IP: 18.208 .226 .222

26 апреля 2023 г., 12:45:47 
1. Немков В. С., Демидович В. Б. Теория и расчег устройств индукционного нагрева. Л.: Энергоатомиздат, 1979

2. Слухочкий $A$. E. Установки индукционного нагрева. Л.: Энергоиздат, 1981.

3. Зенкевич О., Морган К. Конечные элементы и аппроксимация. М.: Мир, 1986.

4. Норри Л., Ж де Фриз. Введение в метод конечных элементов. М.: Мир, 1981.

УдК 621.305

Г.Ф. Егорова

\section{ПЕРИОДИЧЕСКИЕ РЕШЕНИЯ МАТЕМАТИЧЕСКОЙ МОДЕЛИ ПРОЦЕССА ВНУТРЕННЕГО ВРЕЗНОГО ШЛИФОВАНИЯ}

Приводятся результаты исследования вынужденных колебаний, возникающих в прочессе внутреннего врезного илифования вследствие дисбаланса илифовального круга и неблагоприятного соотношения угловых скоростей круга детали. На основе проведенного анализа даются рекомендачии по повымению виброустойчивости прочесса

Математическая модель процесса внутреннего врезного шлифования с учетом формообразующего запаздывания, контактного деформирования в зоне резания, а также упругодиссипативных свойств узлов шпинделей шлифовального круга и детали представляет собой дифференциальное уравнение четвертого порядка с отклоняющимся аргументом нейтрального типа:

$$
\sum_{k=0}^{4} a_{k} x^{(k)}(t)+\sum_{k=0}^{4} b_{k} x^{(k)}(t-\tau)=f(t)
$$

$$
\begin{array}{lr}
a_{0}=\left(k_{1}+c_{3}\right) c_{1} c_{2}+c_{3} k_{1}\left(c_{1}+c_{2}\right) ; & b_{0}=-k_{1}\left(c_{1} c_{2}+c_{3}\left(c_{1}+c_{2}\right)\right) ; \\
a_{1}=\left(k_{1}+c_{3}\right)\left(\xi_{1} c_{2}+\xi_{2} c_{1}\right)+k_{1} c_{3}\left(\xi_{1}+\xi_{2}\right) ; & b_{1}=-k_{1}\left(\left(\xi_{1} c_{2}+\xi_{2} c_{1}\right)+c_{3}\left(\xi_{1}+\xi_{2}\right)\right) ; \\
a_{2}=\left(k_{1}+c_{3}\right)\left(m_{1} c_{2}+m_{2} c_{1}+\xi_{1} \xi_{2}\right)+k_{1} c_{3}\left(m_{1}+m_{2}\right) ; b_{2}=-k_{1}\left(\left(m_{1} c_{2}+m_{2} c_{1}+\xi_{1} \xi_{2}\right)+c_{3}\left(m_{1}+m_{2}\right)\right) ; \\
a_{3}=\left(k_{1}+c_{3}\right)\left(m_{1} \xi_{2}+m_{2} \xi_{1}\right) ; & b_{3}=-k_{1}\left(m_{1} \xi_{2}+m_{2} \xi_{1}\right) ; \\
a_{4}=\left(k_{1}+c_{3}\right) m_{1} m_{2} ; & b_{4}=-k_{1} m_{1} m_{2} .
\end{array}
$$

Здесь $k_{1}$ - коэффициент передачи усилия резания по приращению толщины среза; $c_{2}, c_{1}$ - жесткости упругих систем узла шпинделя шлифовального круга и шпинделя детали, $c_{3}$ - жесткость контакта круга с деталью, $m_{2}, m_{1}$ - массы узлов шпинделя круга и шпинделя детали, $\xi_{2}, \xi_{1}$ - коэффициенты демпфирования упругих систем узлов шпинделей круга и детали, $\tau$ - время одного оборота детали (кольца подшипника).

Основными факторами, влияющими на возникновение вибраций в процессе шлифования, являются плохая балансировка шлифовального круга после его правки, волнистость периферии круга, а также исходная погрешность формы колец подшипников. Все эти факторы аналитически можно описать с помощью задания периодических функций в правой части уравнения (1). Поскольку рассматриваемое уравнение представляет собой линейное уравнение с постоянными коэффициентами, то можно ограничиться определением одночастотных колебаний, возникающих в системе вследствие периодического воздействия с известными частотой и амплитудой. Сложные формы вынужденных колебаний, появляющиеся в процессе при действии сразу нескольких факторов, могут быть получены с помощью суперпозиции найденных одночастотных.

Представим функцию в правой части (1) в виде $f(t)=A_{0} \cos (\omega t)$ и найдем зависимость амплитуды вынужденных колебаний от частоты внешнего воздействия. После всех преобразований эта зависимость будет следующей:

$$
\begin{aligned}
& \operatorname{Re}(P(i \omega))=a_{0}-a_{2} \omega^{2}+a_{4} \omega^{4}-\cos (\tau \omega)\left(b_{0}-b_{2} \omega^{2}+b_{4} \omega^{4}\right)-\sin (\tau \omega)\left(b_{1} \omega-b_{3} \omega^{3}\right) \\
& \operatorname{Im}\left(P(i \omega)=a_{1} \omega-a_{3} \omega^{3}-\sin (\tau \omega)\left(b_{0}-b_{2} \omega^{2}+b_{4} \omega^{4}\right)+\cos (\tau \omega)\left(b_{1} \omega-b_{3} \omega^{3}\right)\right.
\end{aligned}
$$




$$
R=\frac{A_{0}}{\sqrt{\operatorname{Re}(P(i \omega))^{2}+\operatorname{Im}(P(i \omega))^{2}}} .
$$

Расчеты представлены на рис.1, на котором можно видеть резонанс, соответствующий частоте собственных колебаний детали при времени запаздывания 0,03 с.

Второй менее выраженный резонанс наблюдается на частоте близкой к собственной частоте круга. Время запаздывания оказывает существенное влияние на форму и величину резонанса, что видно на рис.2, на котором представлены диаграммы амплитуды вынужденных колебаний модели с различным временем запаздывания. Кроме того, существенными факторами являются как величины коэффициента передачи усилия резания и жесткости контакта круга с деталью, так и отношение этих величин. На рис. 3 представлены те же диаграммы, что и на рис. 2, только в первом случае $k_{1}=10400 \mathrm{H} / \mathrm{Mм}, c_{3}=1030$ H/Mм, а во втором $k_{1}=3300 \mathrm{H} / \mathrm{MM}, c_{3}=5000 \mathrm{H} / \mathrm{Mм}$. Как видно из сравнения этих диаграмм, при выравнивании значений коэффициентов передачи усилия резания и контактной жесткости происходит сдвиг основного резонанса в зону частоты собственных колебаний круга и рост его абсолютной величины. Это вполне объяснимое явление, так как с ухудшением режущей способности круга одновременно возрастает жесткость в зоне контакта круга с деталью, что и вызывает рост амплитуды радиальных колебаний круга.

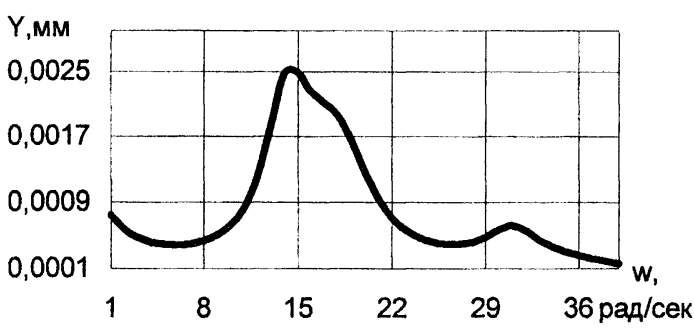

Р и с. 1. Амплитуда внутренних колебаний при времени запаздывания $0,03 \mathrm{c}$

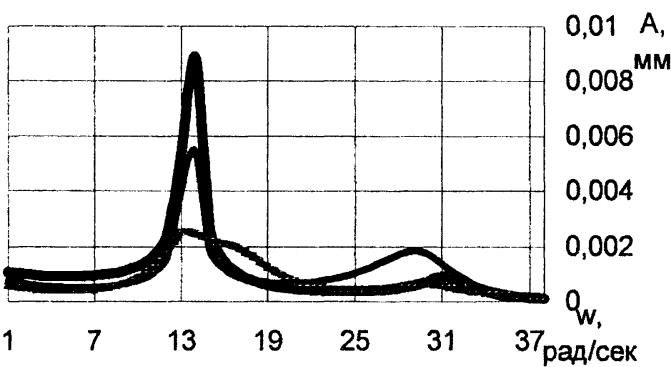

Р и с. 2. Графики амплитуды вынужденных колебаний при различных значениях запаздывания (сверху вниз - 0,01; 0,02; 0,03 )

Исследование модели (1), учитывающей большинство особенностей процесса шлифования, представляет довольно трудоёмкую задачу. Для анализа явлений , возникающих при учете ещё одного запаздывания, связанного с вращением круга, можно рассмотреть следующую упрощенную модель:

$$
\left(c_{3}+k_{1}\right) x^{\prime}(t)-k_{1} x^{\prime}\left(t-\tau_{1}\right)=c_{3}\left(v(t)-v\left(t-\tau_{2}\right)\right)
$$

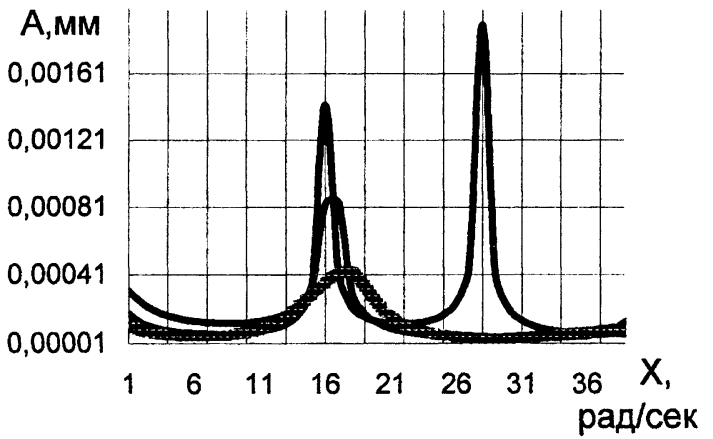

Р и с. 3. Графики амплитуды вынужденньхх колебаний при различньх коэффициентах жесткости контакта где $x(t), x\left(t-\tau_{1}\right)$ - координаты поверхности детали, $\tau_{1}$ - время одного оборота детали, $v(t), v\left(t-\tau_{2}\right)$ - скорость поперечной подачи шлифовального круга, $\tau_{2}$ - время одного оборота круга. Если скорость поперечной подачи круга постоянна, то правая часть равна нулю и решение (2) будет:

$$
x(t)=H\left(1-\left(\frac{c_{3}}{c_{3}+k_{1}}\right)^{\frac{t}{\tau_{1}}}\right) /\left(1-\left(\frac{c_{3}}{c_{3}+k_{1}}\right)^{\frac{t_{k}}{\tau_{1}}}\right),
$$

где $H, t_{k}$ - заданная толщина среза металла и время обработки соответственно. Погрешность, связанная с мнимой частью корней характеристического уравнения, с увеличением времени обработки стремится к нулю. В реальности такого решения быть не может, так как процесс шлифования всегда сопровождается вибрациями, возникающими либо вследствие дисбаланса круга, либо из-за исходной волнистости поверхности детали, либо из-за наличия зазора в подшипниках шпинделей круга и детали. Поэтому практически важным является решение (1), когда к постоянной составляющей скорости поперечной подачи добавляется некоторая периодическая функция:

$$
\left(c_{3}+k_{1}\right) x^{\prime}(t)-k_{1} x^{\prime}\left(t-\tau_{1}\right)=c_{3} A_{\mathrm{B}} e^{i \omega t}\left(1-e^{-i \omega \tau_{2}}\right),
$$


где $A_{\mathrm{B}}, \omega$ - амплитуда и частота колебаний внешнего воздействия. Амплитуда вынужденных колебаний уравнения (3), соответствующих такой правой части, будет иметь вид

$$
R=\left|\frac{c_{3} A_{\mathrm{B}}\left(1-e^{-i \omega \tau_{2}}\right)}{i \omega\left(c_{3}+k_{1}-k_{1} e^{-i \omega \tau_{1}}\right)}\right| .
$$

После очевидных преобразований (4) получим

$$
R=\frac{2 A_{\mathrm{B}} c_{3}\left|\sin \frac{\omega \tau_{2}}{2}\right|}{|\omega| \sqrt{\left(c_{3}+k_{1}\right)^{2}+k_{1}^{2}-2 k_{1}\left(c_{3}+k_{1}\right) \cos \omega \tau_{1}}} .
$$

Наибольшего значения амплитуда вынужденных колебаний будет достигать при значении частоты, при котором:

$$
\left|\sin \frac{\omega \tau_{2}}{2}\right|=1, \omega=\pi(2 k+1) / \tau_{2} ; \quad \cos \omega \tau_{1}=1, \omega=2 \pi n / \tau_{1},
$$

т. е. $\pi(2 k+1) / \tau_{2}=2 \pi n / \tau_{1}, \Rightarrow \tau_{2} / \tau_{1}=(2 k+1) / 2 n$.

Таким образом, самым неблагоприятным является такое сочетание угловых скоростей круга и детали, при котором отношение их будет пропорционально отношению целых чисел, причем четного к нечетному числу. Важным является то, что это соотношение не зависит от частоты возмущения , а определяется заданием угловых скоростей круга и детали. Для проверки адекватности предложенной модели были взяты волнограммы колец подшипников типа 412/01 из стали ШХ-15, обработанных шлифовальными кругами 24A166МIЛ, полученными с помощью прибора Talyrand. Анализ этих волнограмм подтверждает полученный в результате расчетов вывод о том, что в случае неблагоприятного соотношения угловых скоростей круга и детали, волнистость с наибольшей амплитудой на поверхности колец имеет частоту, близкую по значению к частному от деления скорости круга на скорость вращения детали, и не зависит от других факторов.

Полученные результаты позволяют сделать вывод о принципиальной неустойчивости процесса шлифования, так как даже при достаточной жесткости конструкций станка и при отсутствии дисбаланса круга (что позволяет избежать возникновения резонанса вынужденных колебаний на частотах, близких к собственным частотам узлов шпинделей круга или детали), если отношение угловых скоростей круга и детали будет представлять собой рациональную дробь , то в процессе обработки возникнут колебания на частоте, близкой к целой части этой дроби.

Основными рекомендациями по повышению виброустойчивости процесса шлифования являются: во-первых, изменение скорости вращения детали непосредственно во время обработки; во-вторых максимальное увеличение угловой скорости круга; в-третьих уменьшение дисбаланса круга.

\section{БИБЛИОГРАФИЧЕСКИЙ СІПИСК}

1. Егорова Г.Ф., Михелькевич В.Н., Чабанов Ю.А. Автоколебания при шлифовании // Изв. вузов. Машиностроение. 1986, №1. C. 95-101.

\section{УДК 681.51.015.23}

\section{Б.К. Чостковский, С.А. Колпащиков}

\section{АНАЛИТИЧЕСКИЙ МЕТОД ОЦЕНИВАНИЯ СКОРОСТИ ДВИЖУЩЕГОСЯ КАБЕЛЬНОГО ИЗДЕЛИЯ}

Рассмотрен метод оченивания скорости движущегося кабельного изделия по показаниям двух датчиков диаметра. Алгоритм может быть использован для построения устройства измерения скоpocmu.

Существует несколько способов измерения скорости движущегося кабельного изделия: измерение скорости катящимся колесиком, корреляционно спектральный метод и др. Эти методы имеют недостатки. Первый способ имеет низкую точность измерения и воздействует на изоляционное покрытие кабеля, второй же является довольно медленным способом из-за необходимости вычисления автокорреляционных функций. Для оценки корреляционной функции необходимо использовать усреднение по значительным реализациям случайных процессов [1], причем от этого зависит точность оценки. 